\title{
Factors affecting the accuracy of thermal imaging cameras in volcanology
}

\author{
M. Ball ${ }^{1}$ and H. Pinkerton ${ }^{1}$ \\ Received 10 May 2005; revised 26 January 2006; accepted 5 July 2006; published 7 November 2006.
}

[1] Volcano observatories and researchers are recognizing the potential usefulness of thermal imaging cameras both before and during volcanic eruptions. Obvious applications include measurements of the surface temperatures of active lava domes and lava flows to determine the location of the most active parts of these potentially hazardous features. If appropriate precautions are taken, the new generation of thermal imaging cameras can be used to extract quantitative as well as qualitative information on volcanic activity. For example, they can be used to measure the temperature of lava on eruption and to reveal how the crust cools during flow emplacement. This is important for the validation of lava flow models. To ensure that meaningful temperatures are collected, thermal imaging data must be corrected for instrumental errors, emissivity of the surface being imaged, atmospheric attenuation, viewing angle and surface roughness. Controlled laboratory experiments have been undertaken to determine the emissivity of smooth and rough samples and the effects of viewing angle and to quantify the errors. Measured emissivities range from $0.973 \pm 0.002$ for smooth samples of basalt and $0.984 \pm 0.004$ for rough samples. Errors in emissivity-corrected temperatures are within $\pm 15^{\circ} \mathrm{C}$ for lava at $1100^{\circ} \mathrm{C}$. Variations from individual sensor receptors, which provide individual pixel temperature data, were found to be $0.6 \%$ and instrumental errors of the cameras used were $0.1 \%$. Apparent temperatures were found to vary by less than the instrumental error for viewing angles up to 30 degrees from normal to lava, and thereafter increased by $\sim 1^{\circ} \mathrm{C}$ per degree. By increasing the apparent viewing distance of a small vent on Mount Etna from 1.5 to $30 \mathrm{~m}$, the maximum temperature is shown to decrease by $53^{\circ} \mathrm{C}$ due to integrated averaging of radiance over increased pixel areas. At a viewing distance of $250 \mathrm{~m}$ the maximum temperature decreased by $\sim 200^{\circ} \mathrm{C}$ with a further $75^{\circ} \mathrm{C}$ decrease due to atmospheric attenuation for a relative humidity of $50 \%$. However, errors in relative humidity measurements can lead to atmospheric attenuation correction inaccuracies up to $200^{\circ} \mathrm{C}$ at viewing distances of $1 \mathrm{~km}$. We show how temperatures measured using thermal imaging cameras can be corrected to give improved estimates of temperature distributions on the surface of active lava flows.

Citation: Ball, M., and H. Pinkerton (2006), Factors affecting the accuracy of thermal imaging cameras in volcanology, J. Geophys. Res., 111, B11203, doi:10.1029/2005JB003829.

\section{Introduction}

[2] Thermal imaging of volcanoes provides useful information on the surface temperature of lava flows, domes, lakes and other temperature anomalies on volcanoes. Until recently, remote sensing of active volcanic areas was undertaken using either satellites or aircraft [Flynn et al., 2001; Flynn and Mouginis-Mark, 1994; Harris et al., 2004, 2001, 1995; Mouginis-Mark et al., 1991; Mouginis-Mark and Francis, 1992; Oppenheimer and Francis, 1997; Oppenheimer and Rothery, 1991; Pinkerton et al., 2002; Rothery et al., 1988; Rowland et al., 2003; Self and

\footnotetext{
${ }^{1}$ Department of Environmental Science, Lancaster Environment Centre, University of Lancaster, Lancaster, UK.

Copyright 2006 by the American Geophysical Union. 0148-0227/06/2005JB003829\$09.00
}

Mouginis-Mark, 1995; Wright and Flynn, 2003; Zebker et al., 1996]. With the development of hand-held thermal imaging cameras, however, increasing use is being made of helicopter- and land-based thermal imaging data [Flynn et al., 2001; Flynn and Mouginis-Mark, 1994; Harris et al., 2004, 2001, 1995; Mouginis-Mark et al., 1991; MouginisMark and Francis, 1992; Oppenheimer and Francis, 1997; Oppenheimer and Rothery, 1991; Pinkerton et al., 2002; Rothery et al., 1988; Rowland et al., 2003; Self and Mouginis-Mark, 1995; Wright and Flynn, 2003; Zebker et al., 1996].

[3] The latest generation of forward looking infrared (FLIR) thermal imaging cameras have the potential to collect detailed temperature distributions and cooling rates of lava flows. This will allow the cooling component of current models of lava flows to be validated and/or refined [Crisp and Baloga, 1990; Harris and Rowland, 2001; 
Keszthelyi and Denlinger, 1996; Pinkerton and Wilson, 1994]. It will also result in the determination of more accurate effusion rates [Harris et al., 1998]; it will lead to improved understanding of how lavas flow both on Earth and other planets [Head and Wilson, 1986]; and work in this field will help to improve hazard mitigation during volcanic eruptions.

[4] Thermal imaging cameras have been used in volcanology to identify failure planes in the "Laghetto" cone during the 2001 eruption of Mount Etna [Calvari and Pinkerton, 2004], and to record puffing rate of gas emissions from the South East Crater, Mount Etna during the 2001 eruption [Lautze et al., 2004]. Dehn et al. [2002] observed Strombolian eruptions using a FLIR camera on Shishaldin volcano, Alaska, and Lautze et al. [2004] used time series FLIR data to measure lava flow velocities to calculate effusion rates. Bailey et al. [2006] used time lapse FLIR footage on Mount Etna to look at flow formation and thermal flux compared to flow velocity. Thermal imaging data have also been used to assess the reliability of the Dual Band method's assumption of a two thermal component lava flow [Rothery et al., 1988]. The Dual Band method was developed by Dozier [1981] to obtain subpixel temperature temperatures from instruments recording the thermal signal over two wavelength bands. However, Pinkerton et al. [2002] argued for a minimum of four thermal components using radiometer measurements of a lava flow on Kilauea, Hawaii. Using digital thermal images of pahoehoe flows, Wright and Flynn [2003] observed up to seven different thermal components to a flow, and they proposed that thermal images could be used to constrain multiband methods of subpixel temperature distribution analysis from hyperspectral satellite data. During recent eruptions, airborne-derived thermal images have been used to locate and assess activity on Stromboli and Mount Etna, Italy [Calvari et al., 2005] and Mount St. Helens [Vaughan et al., 2005]. While it is reasonable to interpret these thermal anomalies qualitatively, quantitative interpretation of the measured temperatures can only be undertaken once they have been converted into meaningful temperatures.

[5] Temperatures derived from remotely sensed infrared data are subject to errors from (1) atmospheric attenuation by atmospheric scattering caused by particulate material in the atmosphere and absorption by gases; (2) instrument error from instrument noise, drift and systematic offsets in the sensor; (3) incorrect or unknown emissivity of the target where emissivity is defined as the ratio of the theoretical maximum (blackbody) radiance to the radiance of that surface at a given temperature; (4) errors arising from viewing the surface at an oblique angle; and (5) integrated averaging of radiance over increasing pixel areas due to increased viewing distance (decreased resolution).

[6] We address the errors arising from each of these in the following sections and present the results from a well constrained set of laboratory experiments designed to measure emissivity of basaltic lava and the effect of viewing angle on apparent temperatures. The two FLIR thermal imaging cameras used in this investigation (manufactured by FLIR Systems ${ }^{\mathrm{TM}}$ ) are the FLIR ThermaCAM ${ }^{\mathrm{TM}} \mathrm{S} 40$ (S40) and FLIR ThermaCAM ${ }^{\text {TM }}$ S2000 (S2000). Other FLIR cameras, which have been used to acquire data during this research project are the FLIR Systems ${ }^{\text {TM }}$ ThermaCAM PM390 and PM545.

\section{Atmospheric Attenuation}

[7] The thermal imaging systems we use in the field and laboratory operate over two different wavelength ranges (bands) both of which fall in infrared atmospheric windows (Figure 1). Atmospheric attenuation corrections can be applied directly to the recorded images using the internal correction function in cameras. This correction assumes a mean relative humidity $(\mathrm{RH})$ and mean temperature from the camera to the object being measured. However, when viewing over large distances, there may be significant changes in both atmospheric temperature and $\mathrm{RH}$ between the camera and the object under investigation. The in-built software also assumes a uniform viewing distance across an image, but in many cases the viewing distance across an image will not be uniform and can vary by up to hundreds of meters. For these reasons, we consider it inappropriate to use the inbuilt attenuation function. Using individual pixel temperatures spanning the temperature ranges found in images of volcanic thermal images, corrected for measured $\mathrm{RH}$ and viewing distances, it is possible to derive atmospheric attenuation correction curves. These can be modeled (Figure 2) and used to correct thermal data for atmospheric attenuation on a pixel by pixel basis. The errors arising from incorrect $\mathrm{RH}$ values can be in excess of $200^{\circ} \mathrm{C}$ at a viewing distance of $1 \mathrm{~km}$. It is therefore critical that care is taken to measure accurate RH values at the time thermal measurements are made. Variation in $\mathrm{RH}$ and temperature along the viewing path are difficult to determine, but viewing distances can either be measured directly in the field or by using photogrammetry [James et al., 2006].

\section{Instrument Error}

[8] In all instruments used in our measurements, thermal infrared radiation is focused onto the imaging systems focal plane array (FPA) by the camera optics. The FPA is composed of a number of detectors, each representing an individual pixel in the resultant thermal image.

[9] The manufacturers of the S40 camera state that the error of the thermal imaging camera is $\pm 2^{\circ} \mathrm{C}$ or $2 \%$ whichever is greater. At a temperature of $1000^{\circ} \mathrm{C}$ this would represent a measurement error of $\pm 20^{\circ} \mathrm{C}$. Noise of the system is stated to be generally less than $0.1^{\circ} \mathrm{C}$ or $\sim 0.08 \mathrm{RMS}$. However, the DC level (offset) of the sensor fluctuates during operation (A. Grant, FLIR, personal communication, 2004) and has to be corrected for. This is achieved using a shutter that moves in front of the sensor periodically during operation. The FPA sensor images the shutter surface, which is of a known temperature and adjusts the offset of the system. As we show below, this ensures that the accuracy of the camera is within the error margins stated.

[10] To assess errors in temperatures measured using thermal imaging systems, a number of controlled laboratory measurements were performed on different samples over a wide range of temperatures. One of the critical measurements was designed to assess errors in the thermal imaging camera's in-built sensor. For useful measurement of lava flow surface temperatures, an error of less than $2 \%$ is 


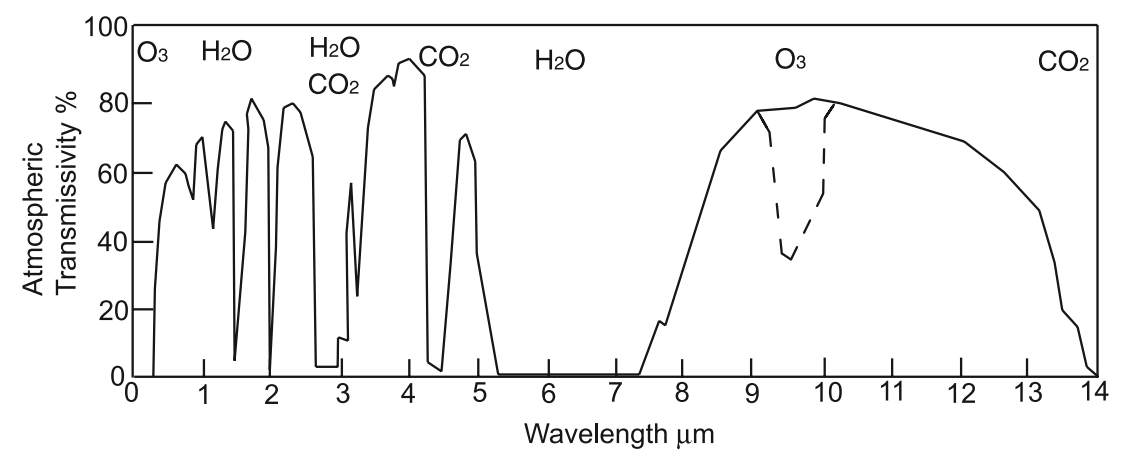

Figure 1. Transmissivity as a function of wavelength with absorption gases marked at relevant locations. FLIR thermal imaging cameras operate in atmospheric windows (a wavelength range over which there is minimal IR atmospheric attenuation). The S40, S2000, and PM545 operate in the 7.5-13 $\mu \mathrm{m}$ range, whereas the PM390 operates in the 3.4-5 $\mu \mathrm{m}$ range. At higher temperatures $\left(>450^{\circ} \mathrm{C}\right)$ the $\mathrm{PM} 390$ uses a flame filter restricting operation to $3.9 \mu \mathrm{m}$. From Sabins [1978].

desirable. An experiment was undertaken to assess the measurement error of the S40 camera at high temperatures. This was done for two reasons. First, if there is any variation in camera accuracy with increased source temperature then a high-temperature source should be used to mimic the temperatures being observed in the field. Second, any measurement error will be more observable at high temperatures because the error is proportional to the source temperature and is therefore less likely to be mistaken as source temperature variation.

[11] The experiment involved heating a sample of polished (to avoid surface heterogeneity) graphite to high temperatures. The surface temperature was measured using the thermal imaging camera and the sample surface/furnace temperature was recorded using an N-type (Nicrosil-Nisil) thermocouple in contact with the sample surface. The calibrated N-type thermocouple was used in conjunction with a calibrated Comark thermocouple meter. Thermal images were recorded at a rate of $1 \mathrm{~Hz}$.

[12] As can be seen from Figure 3, temperatures recorded during the experiment show a sinusoidal trend. This, however, is an artifact of the thermostatically controlled furnace temperature. The mean temperature of the graphite sample surface measured using the $\mathrm{S} 40$ was $844.9^{\circ} \mathrm{C}$. The apparent random noise in the data is $\pm 0.4^{\circ} \mathrm{C}$ (Figure 3). Using an emissivity for graphite of 0.98 [Wolfe and Zissis, 1978], the emissivity corrected temperature measured using the thermal imaging camera was $857^{\circ} \mathrm{C}$. This is $2^{\circ} \mathrm{C}$ higher than the thermocouple temperature of $855^{\circ} \mathrm{C}$ and is well within the manufacturers' specified error of $\pm 2 \%$ giving confidence that the camera is operating well within this specified measurement error.

[13] As can be seen in Figure 4, the high-temperature images of graphite revealed apparent temperature differences between adjacent pixels. To assess whether these are real, or whether they were the results of different FPA detectors outputs to received IR radiation, we extracted temperature profiles across samples of polished graphite at temperatures of 845 and $1035^{\circ} \mathrm{C}$. The sample was positioned slightly differently in the two images although the profiles and accompanying average temperatures were extracted from exactly the same pixel locations within the images (Figure 4).
[14] The graphs in Figure 5 show that the percentage differences from the mean for the same pixels on different areas of a sample at two different average temperatures are almost identical. This suggests that individual pixels on the cameras sensors have a systematic offset. This offset is less than $0.8 \%$ and in most cases less than $\pm 0.6 \%$. However, at an eruptive temperature of $1100^{\circ} \mathrm{C}$ this could result in individual pixel offsets of $\pm 6.6^{\circ} \mathrm{C}( \pm 0.6 \%)$ or $\pm 8.8^{\circ} \mathrm{C}$ $( \pm 0.8 \%)$. This appears to be constant for each pixel. Profiles obtained from sequences of images of the thermally stable graphite samples show that the relative temperature difference between individual pixels remains the same. This offset is only of concern when extracting individual pixel temperatures (e.g., the maximum temperature or temperature profiles made up of individual pixels). When areas or whole image data are extracted (e.g., mean temperatures) the resultant offset will tend to $0^{\circ} \mathrm{C}$.

[15] Finally, the FLIR cameras used in this investigation are both affected by nonuniform FPA sensor performance in response to variations in instrument temperature which

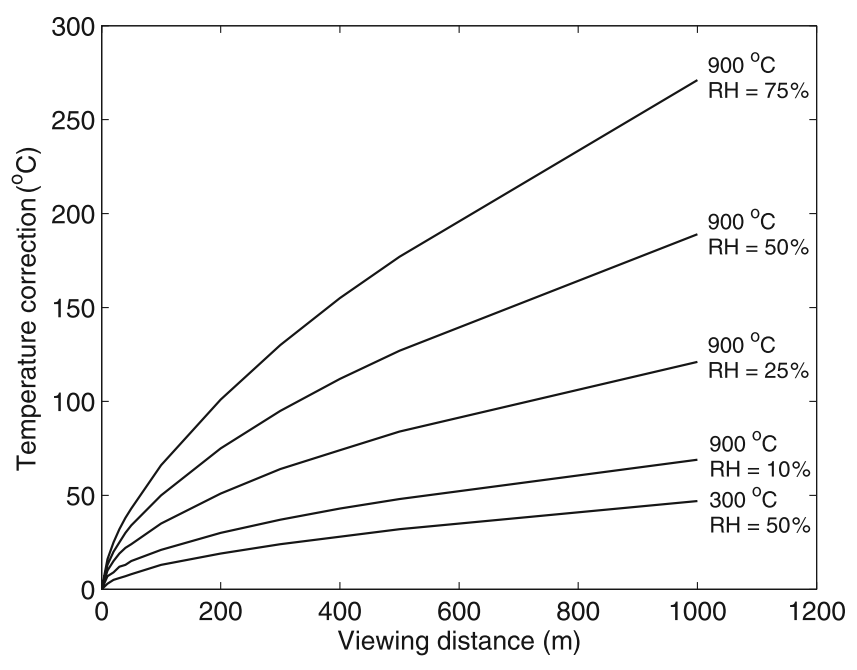

Figure 2. S40 derived correction for atmospheric attenuation with respect to both viewing distance and relative humidity $(\mathrm{RH})$. The RH spans values recorded on Mount Etna in September 2004 (13-75\%). 


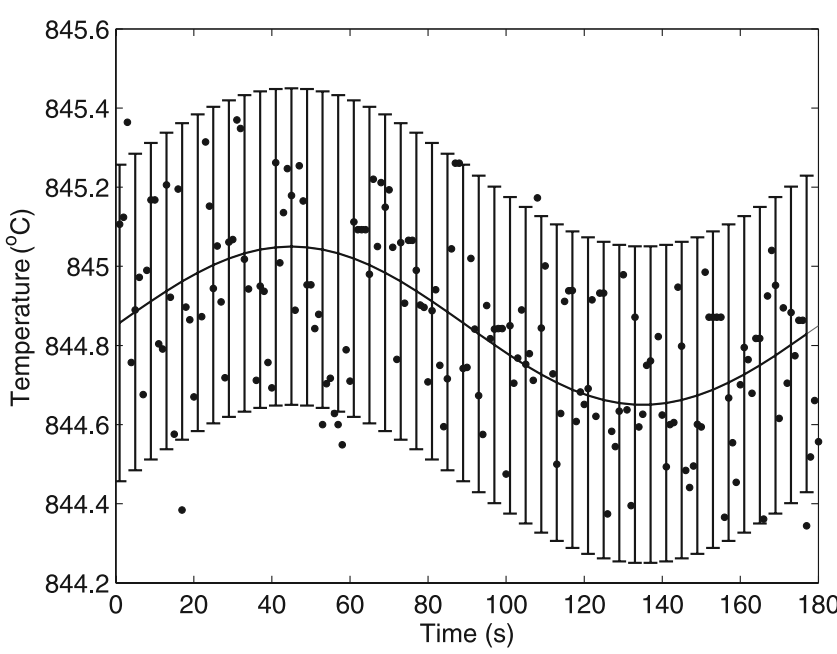

Figure 3. Surface temperatures of a polished graphite sample heated in a furnace to $844.9^{\circ} \mathrm{C}$ measured using the FLIR S0 thermal imaging camera. The sinusoidal trend represents the thermostatically controlled furnace temperature. The error bars represent the extent of the majority of the thermal imaging systems error/noise. The cameras internal shutter was enabled, but anomalous results recorded during shutter operation have been removed.

causes the measured temperature to drift. To correct for any drift in the response, cameras have an automatic shutter that is placed in front of the sensor and its temperature recorded by the FPA sensor. Our laboratory measurements reveal that when the automatic shutter is activated, the temperature variation is $\pm 0.4^{\circ} \mathrm{C}$ at $845^{\circ} \mathrm{C}$, well within the manufacturers' specified error.

\section{Comparison of the Data From the FLIR S40 and S2000}

[16] To calculate emissivity variations with viewing angle, as described in section 7, two thermal imaging cameras were required. Before we can use and compare measurements from both cameras, we need to determine whether there is any difference in temperature measured by both cameras. An experiment in which both cameras were situated above a cooling smooth surfaced sample of Etnean basalt was undertaken to assess measured temperatures recorded by both cameras. The samples were placed in an insulating container with a removable lid, through which a thermocouple was inserted and then placed in a Carbolite Furnaces RHF 1400 furnace and heated to $1050^{\circ} \mathrm{C}$. Once the sample had reached thermal equilibrium it was removed from the furnace and placed on an insulated bench directly below the S40 and S2000 thermal cameras. Thermocouple measurements revealed preexperimental cooling rates of $1{ }^{\circ} \mathrm{C}$ per minute. Both cameras had identical viewing distances. The lid of the insulating container was removed rapidly, and both cameras measured the surface temperature of the sample simultaneously, every $2 \mathrm{~s}$ for a period of $4 \mathrm{~min}$, as it cooled. The difference between the two temperature profiles was plotted as shown in Figure 6. In each of the nine experimental runs, the S2000 recorded a higher temperature than the S40. The maximum temperature difference is $\sim 10^{\circ} \mathrm{C}$ with an average temperature difference of $\sim 7^{\circ} \mathrm{C}$.

[17] Given the systematic differences in temperature between the S40 and S2000 cameras, shown in Figure 6, a correction of $-7^{\circ} \mathrm{C}$ is applied to all S2000 measurements to ensure that the results from both instruments can be compared.

\section{Calculation of Emissivity}

[18] Emissivity is defined by Incropera and De Witt [1985] as the ratio of the radiance emitted by a surface to the radiation emitted by a blackbody at the same temperature. The spectral-directional emissivity of a surface at a given temperature is the ratio of the radiance of the radiation emitted at a particular wavelength in a particular direction to the radiance of the radiation emitted by a blackbody at the same temperature and wavelength. For a surface where the directional distribution of radiation is not diffuse, Incropera and De Witt [1985] define the total, directional emissivity, $e_{\theta}$, as

$$
e_{\theta}(\theta, \phi, T)=\frac{I_{e}(\theta, \phi, T)}{I_{b}(T)}
$$

where $I_{e}$ and $I_{b}$ are the gray and blackbody radiance, respectively, $T$ is the source temperature, $\theta$ and $\phi$ are the zenith and azimuthal angles, respectively, of the spherical coordinate system. Assuming no azimuthal change in emissivity, equation (1) becomes

$$
e_{\theta}(\theta, T)=\frac{I_{e}(\theta, T)}{I_{b}(T)}
$$

If a surface is diffuse then there will be no change in emissivity with $\theta$. However, all real surfaces will exhibit

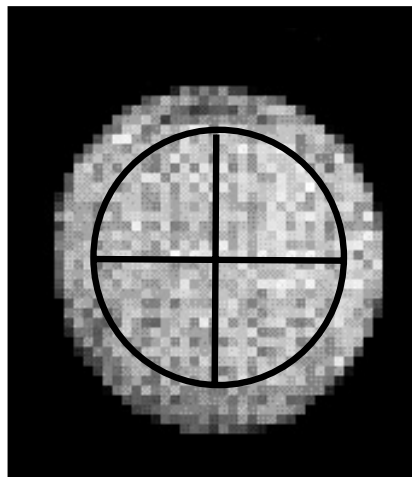

a)

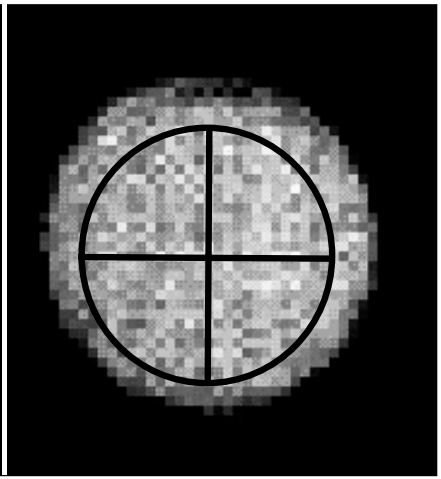

b)
Figure 4. Two thermal images of a thermally stable graphite sample. Figure $4 \mathrm{a}$ has an S40 measured average temperature (within the circle) of $845^{\circ} \mathrm{C}$. Figure $4 \mathrm{~b}$ has an average temperature of $1035^{\circ} \mathrm{C}$. The lines represent temperature profiles shown in Figure 5 (profile lines a and $\mathrm{b}$ are the horizontal lines in Figures $4 \mathrm{a}$ and $4 \mathrm{~b}$, respectively, and $c$ and $d$ are the vertical lines in Figures $4 a$ and $4 b)$. All profiles are in the same position within the field of view of the camera (so occupy the same pixels) but are offset slightly over the samples. 

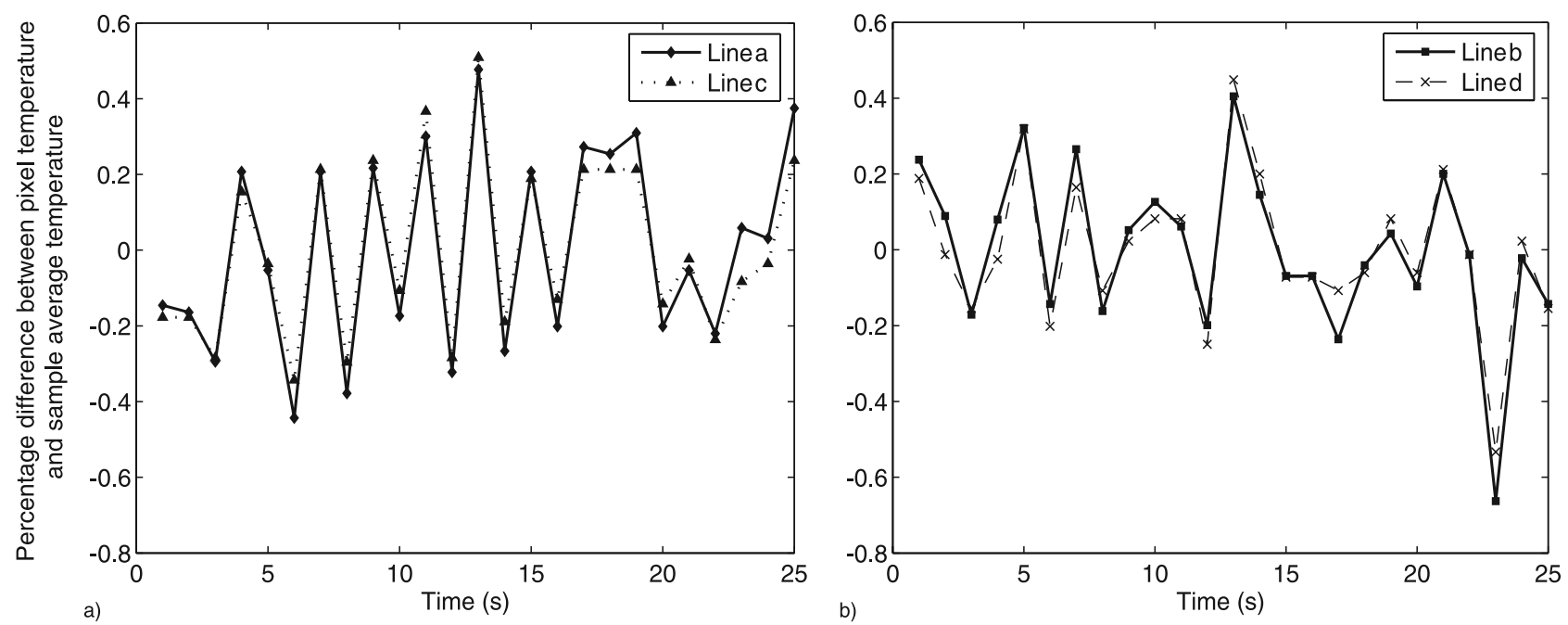

Figure 5. Percentage difference of each pixel value on profiles a-d from the average temperature of the profiles corresponding sample. The average temperatures are measured from within the circles shown in Figure 4. The profiles reveal that the percentage offset for individual pixels remains constant for varying measured temperatures.

some departure from diffuse behavior [Incropera and De Witt, 1985]. This deviation away from diffuse behavior results in a change in emissivity with $\theta$.

[19] Surface roughness will play a part in the diffusivity of a surface. However, for the purpose of the experimental determination of the variation of emissivity with viewing angle, any change in radiance $I_{e}$ with $\theta$ will be considered as being due to a change in emissivity.

[20] Published emissivities for basaltic lava range from 0.74 [Burgi et al., 2002] to 1.00 [Pinkerton et al., 2002] (Table 1). These emissivities have been derived from field data or through laboratory experiments.

[21] Software in FLIR Systems ${ }^{\text {TM }}$ thermal imaging cameras converts the measured radiance to Kelvin and finally outputs pixel temperatures in ${ }^{\circ} \mathrm{C}$. Any postprocessing of the data, to convert temperatures back to radiance (e.g., for adjustment of blackbody temperatures to values corresponding to surface emissivity), has to be undertaken with maximum accuracy to reduce post processing generated error. Three methods can be used to calculate the radiance for a given temperature. Radiance is calculated using equation (3). Integration of this equation between any two wavelengths will give the total blackbody radiance $\left(E_{b}\right)$ corresponding to any particular temperature $(T)$ and wavelength range (band). Integration over the entire range of wavelengths $(0 \leq \lambda \leq \infty)$ gives

$$
\begin{gathered}
E_{b}=\int_{0}^{\infty} I_{\lambda b} d \lambda \\
E_{b}=\sigma T^{4}
\end{gathered}
$$

Equation (4) is known as the Stefan-Boltzmann law where $\sigma=5.67051 \times 10^{-8}$ is the Stefan-Boltzmann constant.

[22] To calculate the radiance given off by a body over a particular wavelength range, several methods can be used. Incropera and De Witt [1985] show that the fraction of the area under the curve defined by Planck's law between $\lambda=0$ and $\lambda=\mathrm{C}_{1}$ is

$$
F_{(0 \rightarrow \lambda)}=\frac{\pi \int_{0}^{\lambda} I_{\lambda, b} \cdot d \lambda}{\pi \int_{0}^{\infty} I_{\lambda, b} \cdot d \lambda}=\frac{\int_{0}^{\lambda} I_{\lambda, b} \cdot d \lambda}{\sigma T^{4}}
$$

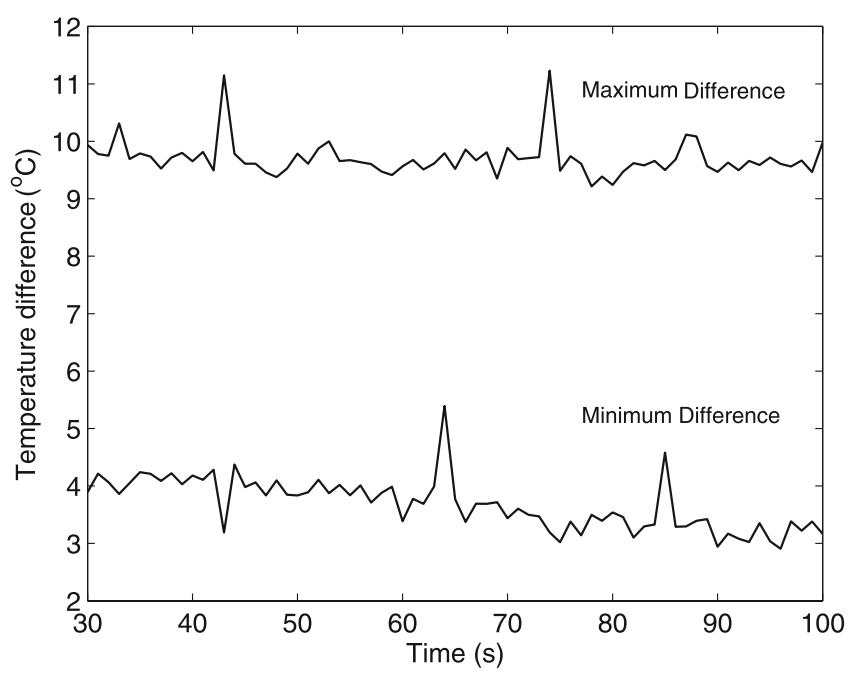

Figure 6. Results from the camera comparison experiments. Nine experimental runs were undertaken. Both the S40 and S2000 were at normal viewing angles and the same viewing distance. The results show average temperature differences between measured cooling temperature trends for a heated basalt sample. The data are from the experimental runs with the maximum and minimum temperature difference between the two cameras. Spikes in the data are where the automatic shutter has been activated. 
Table 1. Emissivities Used in Previous Research Using Remotely Sensed IR Data

\begin{tabular}{cllcl}
\hline Emissivity & \multicolumn{1}{c}{ Location } & Instrument & Wavelength, $\mu \mathrm{m}$ & Source \\
\hline 0.74 & Erta'Ale, Ethiopia & pyrometer & $1.1-1.7$ & Burgi et al. [2002] \\
0.95 & Hawaii & radiometer & $8-13$ & Pinkerton et al. [2002] \\
1 & Hawaii & radiometer & $0.8-1.1$ & Pinkerton et al. [2002] \\
0.95 & Hawaii & radiometer & $8-13$ & Harris et al. $[1998]$ \\
\hline
\end{tabular}

$$
F_{(0 \rightarrow \lambda)}=\frac{\pi c_{1 L}}{\sigma} \int_{0}^{\infty} \frac{1}{(\lambda T)^{5}\left[\exp \left(c_{2} / \lambda T\right)-1\right]} \cdot d(\lambda T)
$$

Therefore, for any particular wavelength range from $\lambda_{1}$ to $\lambda_{2}$ the fraction of the area under the curve is represented by

$$
F_{(\lambda 1 \rightarrow \lambda 2)} \frac{\int_{0}^{\lambda 2} I_{\lambda, b} d \lambda-\int_{0}^{\lambda 1} I_{\lambda, b} d \lambda}{\sigma T^{4}}=F_{0 \rightarrow \lambda 2}-F_{0 \rightarrow \lambda 1}
$$

From equation (7) it can be seen that the total radiance of a particular band is proportional to the fraction of radiance from $\lambda=0 \rightarrow \lambda=\lambda_{2}$ minus the fraction of radiance from $\lambda=0 \rightarrow \lambda=\lambda_{1}$. These values can be obtained from Incropera and De Witt [1985] for any particular band. The data used in this work have been captured using thermal imaging cameras operating over two different band widths. These are summarized in the caption to Figure 1.

[23] Although Incropera and De Witt [1985] provide look-up tables for the values required in equation (7) (the integration is nontrivial) a more versatile method of radiance calculation was required for any wavelength range at any temperature. Two similar methods that can be used to calculate radiance are shown in Figure 7. Calculating the radiance using the radiance of the central wavelength (Figure 7a) of the spectral band multiplied by the band range is a crude method especially with large bandwidths.
The method used here to calculate radiance is shown in Figure $7 \mathrm{~b}$. The bandwidth is subdivided into several areas and the sum of the individual areas gives the radiance. For all calculations 1000 sections were used.

\subsection{Laboratory Measurements of Emissivity of Etnean Lava}

[24] Since a $10 \%$ drop in emissivity from 1.00 to 0.90 results in a measured temperature difference of $83.4^{\circ} \mathrm{C}$ at magmatic temperatures, a rigorous method of measuring emissivity of lava is required to reduce emissivity induced error to an acceptable level.

[25] Two sets of measurement methods were used to determine emissivity over a range of temperatures. In both measurements, two cameras were used, in conjunction with a thermocouple for direct measurements. Direct measurements were made using an N-type thermocouple. Both thermal imaging cameras operate in the $7.5-13 \mu \mathrm{m}$ wavelength range, and both were set up to output temperatures assuming an emissivity of 1 . No atmospheric attenuation corrections were applied during data recording. Both cameras have an automatic internal image correction, which adjusts the camera temperature scale to the image. During all experiments the internal image corrections on the cameras were switched off to prevent nonsynchronized automatic corrections by the cameras. All measurements of basalt temperatures were made over a range of temperatures, which included typical lava flow emplacement temperatures.
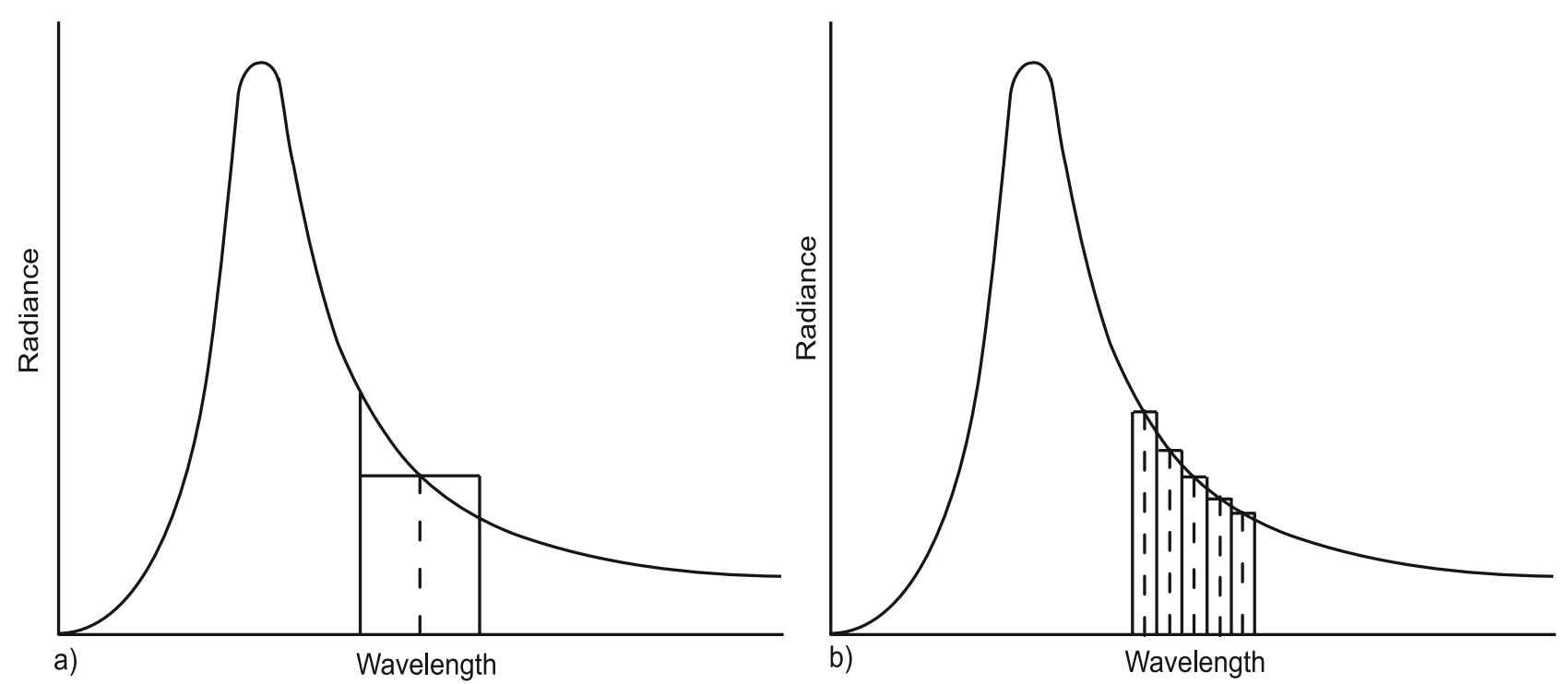

Figure 7. Simplified method for calculating radiance. (a) Using a central wavelength assumes the hatched areas are the same. (b) By using multiple divisions this error is reduced and a better approximation of the radiance is obtained. 


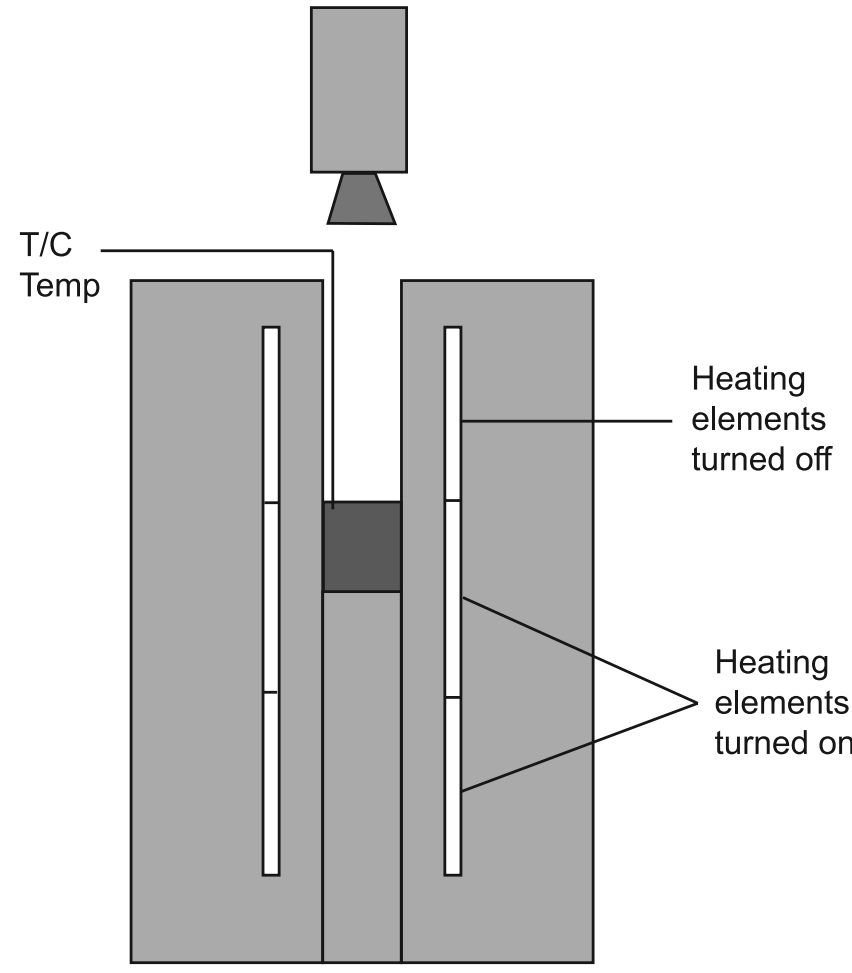

Figure 8. Experimental setup for direct determination of emissivity using a tube furnace. The sample is placed in the center of the tube furnace ( $\sim 60 \mathrm{~cm}$ from the open top) with the upper heating element switched off. Temperatures are recorded with both the thermal imaging camera and the thermocouple $(\mathrm{T} / \mathrm{C})$. The diameter of the tube furnace was $75 \mathrm{~mm}$. The viewing distance was $1 \mathrm{~m}$.

[26] Because of possible compositional effects on emissivity, basaltic samples from Mount Etna were used to constrain the emissivity of Etnean basalt. Values of emissivity were measured at a viewing angle at right angles to the surface of the sample. Angular variations in emissivity of both smooth and rough surfaced samples are investigated in section 7.

[27] During typical field measurements using FLIR cameras, pixel side lengths will range from $\mathrm{mm}$ to $\mathrm{m}$. Therefore experiments to determine emissivity should derive an emissivity that can be applied at all resolution scales. As the S40/ S2000 target distance increases so does pixel area and therefore the temperature recorded is derived from an integrated radiance emitted from the increased target area. An emissivity representative of any scale is required; therefore the average temperatures of the sample were used to reduce the effects of small-scale heterogeneity. For emissivity calculation the blackbody radiance was taken to be that derived from the thermocouple measurements of sample temperature. The gray body radiances were those derived from the S40 and S2000 temperatures.

\subsection{Determining Emissivity of a Thermally Stable Sample at a Normal Viewing Angle}

[28] The methodology to determine the emissivity of basalt was as follows. Samples of Etnean basalt were melted in a crucible at $1200^{\circ} \mathrm{C}$ to produce a smooth surface. An N-type thermocouple was placed into the sample during sample preparation. The sample was positioned in the central area of a tube furnace (Figure 8) which was open at the top, thus allowing the S40 to view the sample, but closed at the bottom to reduce the thermal gradient within the furnace. The furnace consisted of a $900 \mathrm{~mm}$ long tube around which heating elements were positioned. There were three tiers of elements; a lower, middle and upper tier. The sample was positioned next to the middle tier of heating elements. To minimize any IR reflection from the surface of the sample, the upper tier of heating elements was switched off. The temperature of the furnace was ramped up at approximately $100^{\circ} \mathrm{C}$ intervals, and the surface temperature was recorded from above by the S40 once the temperature had stabilized at each level. The thermocouple was used to determine sample temperatures at all times. The experiment was also carried out with a rough sample. In this instance the thermocouple was placed on the sample surface to record the stabilized temperature.

[29] The results of two runs of this experiment are shown in Figure 9 and they reveal that the smooth sample has an emissivity range of 0.971 to 0.975 (mean of 0.973 ) over the temperature range used while the rough samples have an emissivity range of 0.98 to 0.987 (mean of 0.983 ). Variation of emissivity with temperature does not appear to exhibit any systematic trend.

\section{Error Propagation}

[30] Measurement errors incurred through operation of the S40 fall in to two categories; Instrument errors and external factors. Errors in measured temperatures induced by external factors are predominantly due to incorrect atmospheric attenuation corrections. These can be reduced through rigorous assessment of the atmospheric conditions (relative humidity, temperature etc) along the viewing path and an accurate measurement of viewing distance for all

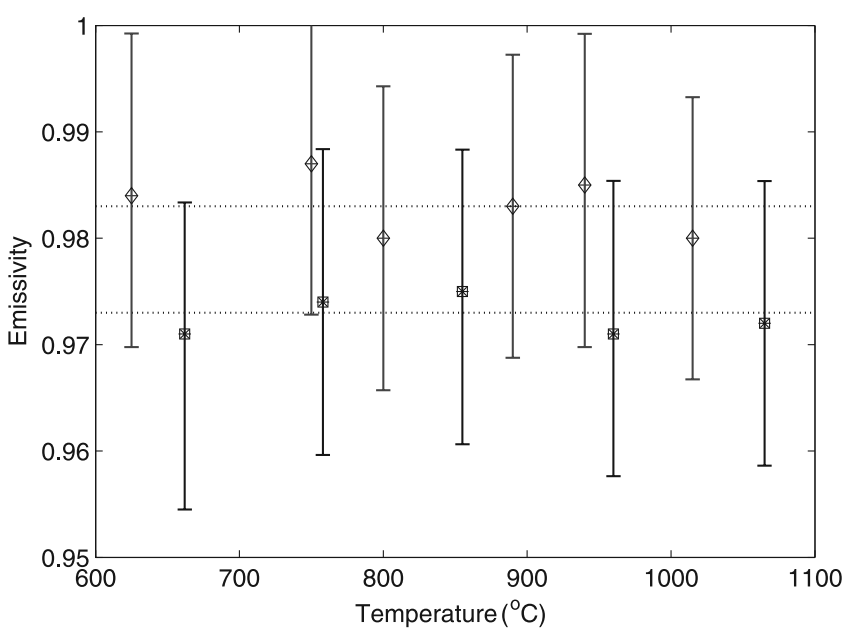

Figure 9. Calculated emissivities for smooth and rough samples from the tube furnace experiments. Error bars represent emissivity ranges for S40 measured temperature errors of $\pm 1 \%$. 


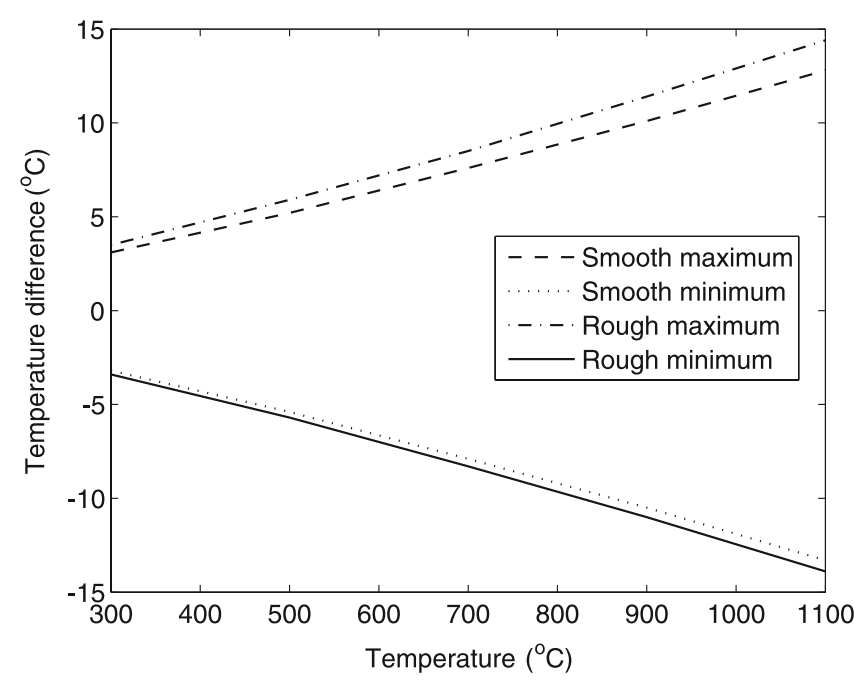

Figure 10. Temperatures corrections determined from emissivity errors. Assuming either rough or smooth basalt the corrections show the range of temperature corrections to be applied for a variance from the smooth or rough emissivity of 0.973 and 0.983 , respectively, based on the emissivity errors in Figure 9.

pixels in the image. Both of these require more detailed analysis with increased viewing distances as they will vary both along the view path (atmospheric effects) and across the image (viewing distance and atmospheric effects) especially if viewing obliquely. The user needs to make an assessment of how accurately the attenuation and distance measurements need to be made in order to obtain useful temperature measurements.

[31] Instrument error has been quantified during laboratory experiments as being three component. The first is random noise at a level of $\pm 0.4^{\circ} \mathrm{C}$. The second arises from systematic pixel offset and is fixed for individual pixels. When analyzing the images this offset needs to be taken into account when analyzing individual pixels. However, when looking at total radiance, average temperature etc the systematic offset can be ignored. The third instrument error arises from time-dependent drift. This will produce a time varying temperature which affects the entire instrument sensor. This is corrected for automatically by internal calibration during measurements. The lab experiments have shown that the maximum total instrument error is $<1 \%$ based on the random noise and pixel offsets discussed in section 3 (the manufacturers quoted error is $\pm 2 \%$ ).

[32] Consequently, when calculating emissivities the instrument measurement error should be taken into account. Figure 9 shows the ranges of emissivity for the measured temperatures with error bars representing the emissivity range for the associated temperature error. This can in turn be used to calculate a correction for all measured temperatures depending on the original emissivity used (i.e., emissivity corresponding to rough or smooth basalt). Corrections are calculated using the extreme emissivity values (those representing the minimum and maximum emissivities from the rough and smooth error bars). Figure 10 shows the possible corrections for the emissivity corrected temper- atures. Figure 10 can therefore be used to assign errors to emissivity corrected temperatures.

\section{Angular Variation in Emissivity}

[33] When making measurements of surface temperatures of lava flows in the field, there are few occasions when it is possible to use a thermal imaging camera at a normal viewing angle to the surface of the flow. In the following experiments the effect of viewing angle are investigated.

[34] Sobrino and Cuenca [1999] and Labed and Stoll [1991] showed experimentally that the emissivity of a surface may change as a function of the viewing angle to that surface, with maximum emissivity at normal viewing angles to the emitting surface. Dozier and Warren [1982] showed that the angular variation in emissivity caused changes in snow brightness temperature of up to $3 \mathrm{~K}$ over a viewing angle range of $75^{\circ}$. Labed and Stoll [1991] measured the apparent temperature of various samples (soils and sand) at a fixed temperature using a spectroradiometer over a range of viewing angles. The spectroradiometer measured IR radiation reflected from a series of mirrors one of which was attached to a goniometer. This mirror could be rotated about all angles $\left(0^{\circ}-90^{\circ}\right)$ from the horizontal and reflects the IR radiation from the target sample. Sobrino and Cuenca [1999] used a similar method in the field. They assumed that as long as there was no direct sunlight or wind at the time of the experiment, the field samples could be assumed to be thermally stable for periods up to $2 \mathrm{~min}$. Both concluded that emissivity decreases with increased viewing angle. In several cases this decrease was small up to a viewing angle of $\sim 60^{\circ}$ from the horizontal. However, as the viewing angle was reduced, the emissivity decreased by up to $\sim 15 \%$.

[35] The aim of this experiment was to determine whether there was a similar variation in emissivity with viewing angle for basaltic lava at eruptive/lava flow emplacement temperatures. However, the need to make measurements at high temperatures required a more complex procedure than that used by Labed and Stoll [1991].

[36] For obvious geometrical reasons, it is not possible to use a tube furnace, or any other type of conventional furnace to make emissivity measurements over a range of viewing angles. To allow measurements to be made over a wide range of viewing angles, measurements had to be made outside the furnace as the samples cooled. A rigorous experimental procedure was devised to ensure that simultaneous measurements were made both at an angle normal to the surface and at a range of fixed angles. Using a cooling sample has the advantage that it allows apparent temperature measurements to be made over a range of surface temperatures.

[37] The method developed to determine the effect of viewing angle involved two separate thermal imaging cameras (S40 and S2000). One measurement of temperature was taken normal to the surface of the basalt sample by a control camera (S2000), while a separate measurement was made at varying viewing angle from the normal (S40). The relative temperature difference between the S40 and S2000 cameras is then used to calculate a relative emissivity difference. Combined with a knowledge of the emissivity 


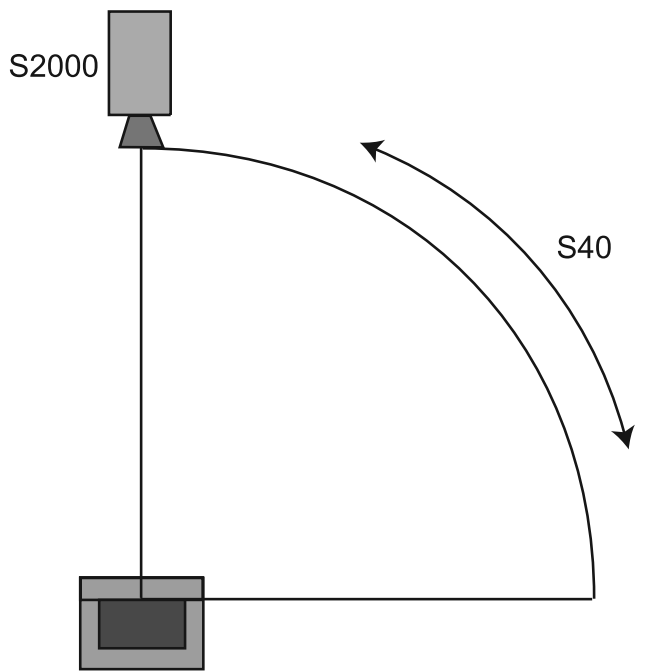

Figure 11. Experimental setup for an assessment of angular variation of emissivity. The S40 was rotated about the sample and fixed at 10-degree intervals. The S2000 was fixed at 90 degrees from the horizontal.

of the sample obtained from the tube furnace experiments, the value of emissivity with viewing angle can be obtained.

\subsection{Angular Variation of Emissivity Experimental Methodology}

[38] Samples were prepared as described in section 5.2 by melting basalt in a furnace to provide a smooth surface. The cameras were attached to a framework, consisting of a fixed attachment point for one camera (the control camera) and a rotating arm with a camera attachment point at the end (Figure 11). The basalt sample was located at the base of the framework and both cameras were focused on the center of the sample. The framework was designed such that the camera lenses were $1000 \mathrm{~mm}$ from the center of the surface of the sample at all times, and the fixed camera viewing angle was normal to the surface of the sample. The point of rotation for the S40 attached to the rotating arm was the center of the basalt sample surface. The rotating arm was fixed at 10-degree intervals from the normal. As both cameras were required to look at the sample with a normal viewing angle but could not occupy the same space, the control camera was located to one side of the $\mathrm{S} 40$ (which is attached to the rotating arm) when at an angle of 90 degrees to the horizontal. The sample was then removed from the furnace and placed directly beneath the S2000 as indicated in Figure 11. Once the sample was in position, image recording was initiated and the insulating lid was removed. Images were recorded from each camera every $2 \mathrm{~s}$ as paired images over a period of $4 \mathrm{~min}$.

\subsection{Rough Samples}

[39] Experiments to determine the combined effects of roughness and viewing angle were applied to an unaltered (i.e., no secondary melting in the furnace) sample of Etnean basalt. The sample was subjected to the same experimental methodologies as the smooth basalt samples except that they were heated to slightly lower temperatures in the furnace to prevent any deformation of the surface textures.
The experiment was designed to assess the effect of surface roughness on the temperature differences between the two cameras. This situation is analogous to field measurements where the surface of a lava flow can have a varied, almost chaotic, surface texture. The sample had a generally horizontal surface but it clearly exhibited distinct roughness with small "pits" a few millimeters across and deep.

\subsection{Results: Angular Variation in Emissivity for Smooth Samples}

[40] Figure 12 shows average temperature differences over the 4 min image capture period, from two sets of experiment runs corrected for the average temperature difference from the calibration. It can be seen that temperature difference is not constant with viewing angle. From 0 to 30 degrees from the vertical the overall temperature difference is $1^{\circ} \mathrm{C}$. However, from 40 to 80 degrees, there is a marked increase in the apparent temperature difference.

[41] Figure 13 shows the temperature difference profiles used to calculate average temperature differences. It can be seen that there is a decrease in temperature difference with time, especially at lower angles from the horizontal. Since emissivity is a ratio of gray body to blackbody radiance, as the blackbody radiance decreases with cooling the gray body radiance has to decrease proportionately to maintain the same emissivity. This results in a decrease in temperature difference as observed in Figure 13.

[42] To confirm this, emissivities were calculated for each experimental run using the temperature differences at the beginning and end of the cooling profiles. An emissivity of 0.975 (from the tube furnace experiments) was used for normal viewing angles. Any temperature differences within error of $0^{\circ} \mathrm{C}$ were also given an emissivity of 0.975 . Table 2 shows the results of calculating emissivity at the beginning and end of the cooling profiles. Overall there is excellent agreement between corresponding emissivities. This indicates that there is no change in emissivity with temperature

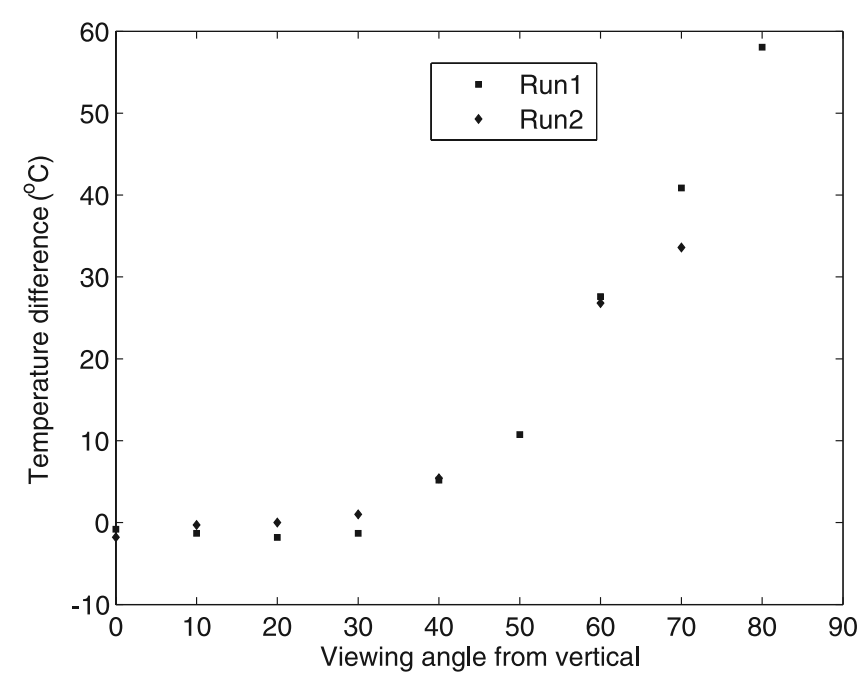

Figure 12. Temperature difference between the S40 and S2000 cameras with the S40 at various viewing angles. Temperatures are corrected for calibration differences between the two cameras. 


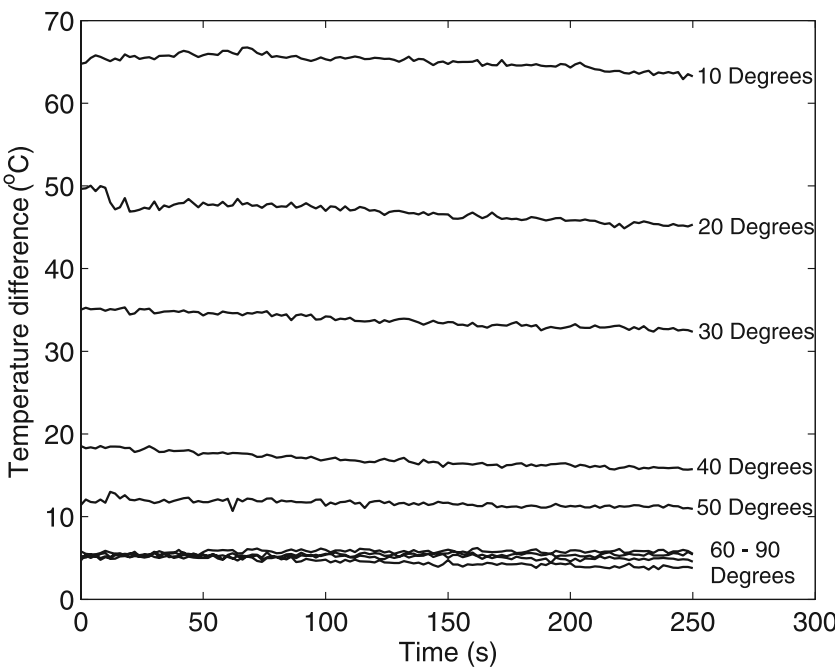

Figure 13. Mean temperature differences over an experimental run between the S40 and S2000 for varying S40 viewing angles. Angles are measured from the horizontal.

over the temperature ranges of the experiments. This is in agreement with the tube furnace emissivity experiments.

[43] Figure 14 shows the averaged emissivities from Table 2 plotted against viewing angle. Emissivity remains constant from 90 to 60 degrees from the horizontal and rapidly drops from 50 to 10 degrees.

\subsection{Angular Variation in Emissivity for Rough Samples}

[44] While the results from the experiment using a smooth sample clearly show a reduction in emissivity with increasing viewing angle from normal, this situation may not be applicable to field data. Smooth lava surfaces are unlikely to be seen in most lava flow fields or lava lakes because they will generally be rougher than the smooth sample used in the smooth emissivity runs described in section 7.3 .

[45] It can be seen from Figure 15 that the apparent temperature difference for the rough sample increased with increasing viewing angle from the vertical. However, this may not be due to a reduction in emissivity with viewing angle. Visual inspection of the sample showed that "pits" in the surface of the sample remained hotter during cooling. The camera was unable to detect these higher temperatures

Table 2. Emissivities Calculated at the Beginning and End of the Cooling Trends From the Angular Experiments

\begin{tabular}{|c|c|c|c|c|c|c|c|c|c|}
\hline \multirow[b]{2}{*}{ Emissivity } & \multicolumn{9}{|c|}{ Angle, deg From Horizontal } \\
\hline & 90 & 80 & 70 & 60 & 50 & 40 & 30 & 20 & 10 \\
\hline \multicolumn{10}{|c|}{ Run 1} \\
\hline Start & 0.975 & 0.975 & 0.975 & 0.975 & 0.965 & & 0.929 & 0.919 & \\
\hline End & 0.975 & 0.975 & 0.975 & 0.975 & 0.964 & & 0.920 & 0.898 & \\
\hline Average & 0.975 & 0.975 & 0.975 & 0.975 & 0.965 & & 0.925 & 0.909 & \\
\hline \multicolumn{10}{|c|}{ Run 2} \\
\hline Start & 0.975 & 0.975 & 0.975 & 0.975 & 0.966 & 0.954 & 0.930 & 0.903 & 0.880 \\
\hline End & 0.975 & 0.975 & 0.975 & 0.975 & 0.965 & 0.951 & 0.911 & 0.870 & 0.850 \\
\hline Average & 0.975 & 0.975 & 0.975 & 0.975 & 0.966 & 0.953 & 0.921 & 0.887 & 0.865 \\
\hline
\end{tabular}

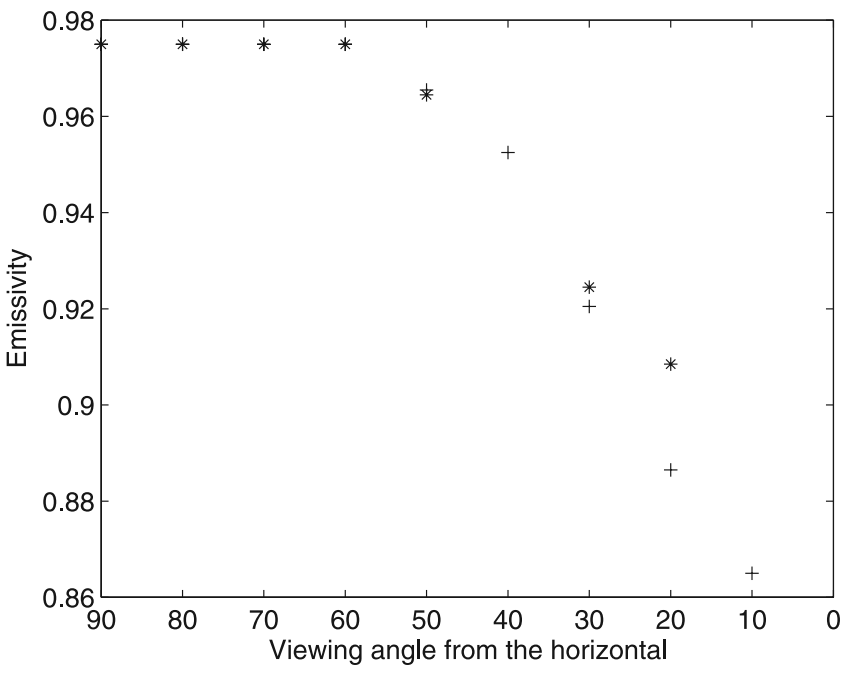

Figure 14. Emissivities at different viewing angles calculated for two runs of the experiment. A normal viewing angle emissivity of 0.975 is assumed.

at increased viewing angles from the vertical because the "pits" were obscured by higher surface topography. Therefore lower average temperatures were recorded at increased angles from the vertical because of surface roughness. This means it would be difficult to extract any variations in emissivity from the data as the temperature differences appear to be controlled by surface texture.

\section{Application of Corrections to Field Data}

[46] The laboratory results show that there is a significant decrease in emissivity at increasingly oblique viewing angles when imaging a smooth basalt surface. This decrease is less pronounced with rough samples. The experimental

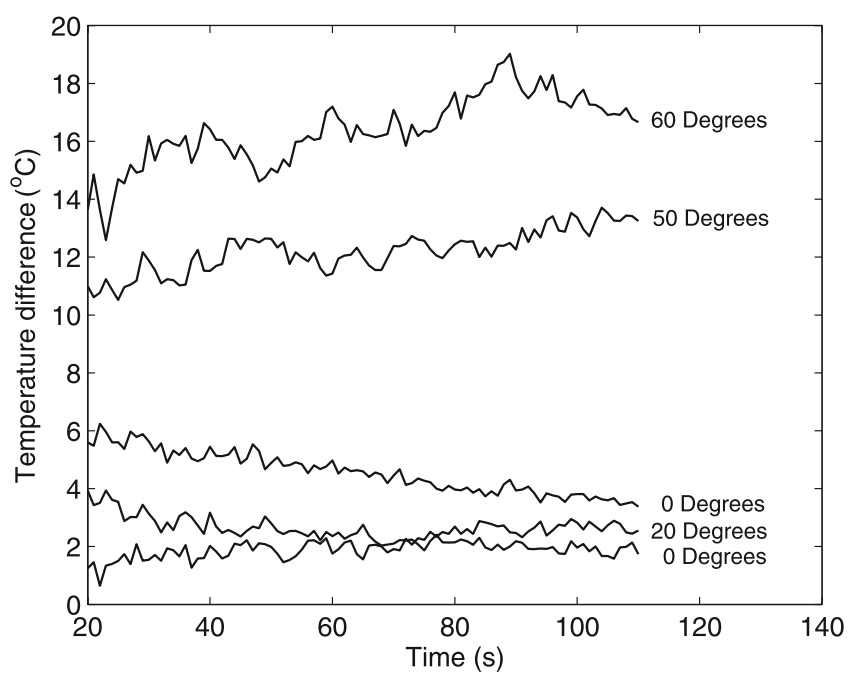

Figure 15. Apparent temperatures of rough samples as a function of viewing angle from vertical. The results show an increase in temperature difference between the two cameras at 50 and 60 degrees. This difference is dominated by the effects of surface roughness. 


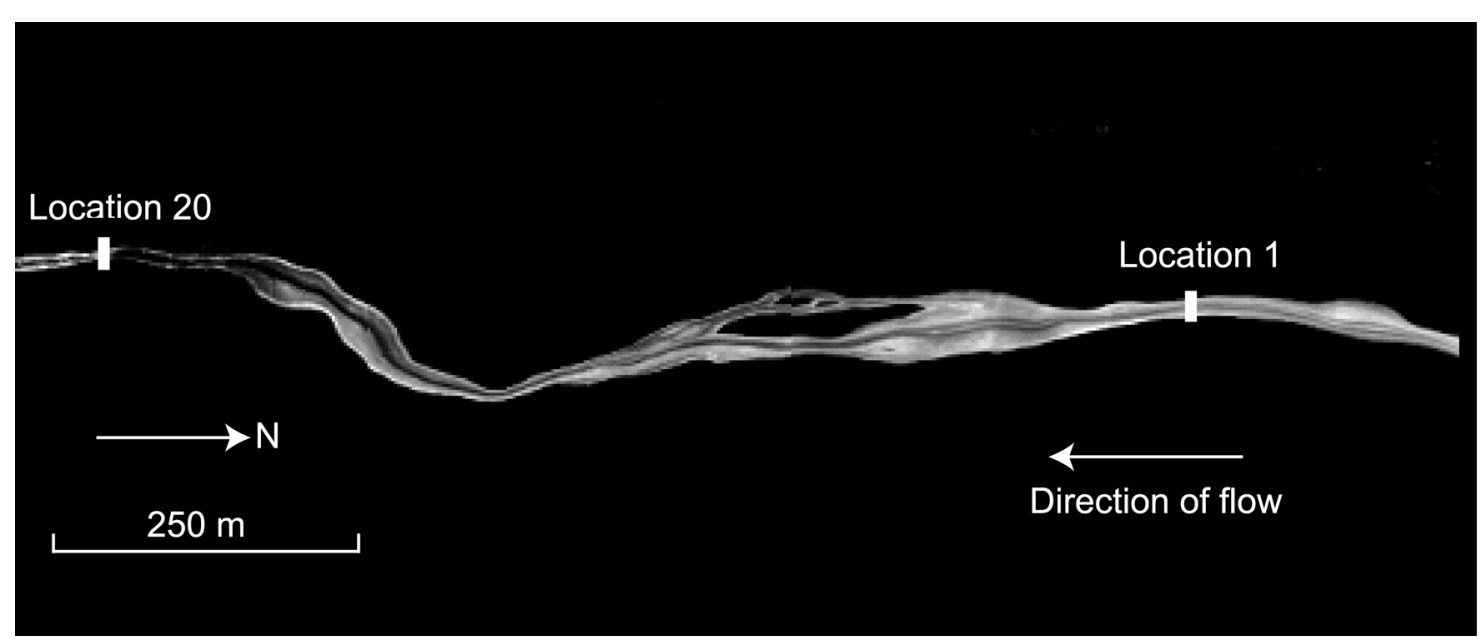

Figure 16. Thermal image of an Etna 2001 lava flow taken from a helicopter $\sim 1000 \mathrm{~m}$ above ground level.

results using a normal viewing angle allow us to define values of emissivity for basalt with two different surface textures. For a smooth surface the emissivity is 0.973 and for a rough surface (mm-scale roughness) it is 0.983 .

[47] The laboratory measurements can now be used, together with atmospheric attenuation corrections, to correct field-based thermal images. Figure 16 is a mosaic of helicopter based images of the flow erupted from the $2100 \mathrm{~m}$ vent during the 2001 flank eruption of Etna. These images are used to highlight differences between uncorrected and corrected temperatures measured using the thermal imaging cameras. The highlighted area (location 1-20) in Figure 16 has been divided into 20 sections representing equal lengths of flow. The mean section temperature (thresholded to include pixels with a temperature $>230^{\circ} \mathrm{C}$ ) has been measured. Figure 17 shows the temperature profiles from the sections. The data have also been corrected for emissivity and RH values over the range measured by the authors in the field on Etna in 2004. Because of the near normal viewing angle no viewing angle correction for temperature variations are required.

[48] The data in Figure 17 show a cooling trend as the lava progresses along the channel. There is a drop in average temperature of $\sim 0.18^{\circ} \mathrm{C} \mathrm{m}^{-1}$ for the raw data rising to $0.25^{\circ} \mathrm{C} \mathrm{m}^{-1}$ for an $\mathrm{RH}$ of $75 \%$. Using a flow velocity of $0.5 \mathrm{~m} \mathrm{~s}^{-1}$, this results in cooling rates of $0.09^{\circ} \mathrm{C} \mathrm{s}^{-1}$ for the raw data and $0.125^{\circ} \mathrm{C} \mathrm{s}^{-1}$ and when the $\mathrm{RH}=75 \%$. These differences in cooling rates between uncorrected and $\mathrm{RH}$ corrected data highlight the importance of measuring relative humidity at the time of data collection.

\section{Effect of Image Resolution on Temperature}

[49] Viewing distance is a significant factor in determining surface temperatures. When thermal imaging cameras are used within a few meters of a lava flow, the effect of integrated averaging of the radiance over a pixel area is reduced. Because of shorter viewing distances, the effect of atmospheric attenuation is also reduced. Ultimately a viewing distance close to zero would provide the highest resolution and best resolved temperatures, although this is impracticable. However, appreciating how much resolution is required to obtain useable temperatures is important for quantitative analysis of data.

[50] Figure 18a shows a thermal image of a small vent on Etna during the 1999 eruption at a viewing distance of $1.5 \mathrm{~m}$. This image shows that on eruption, there are significant surface temperature variations over the surface of the flow with differences of temperature, well above that arising from FPA errors, between adjacent pixels. This highlights the problems faced in developing cooling models, which usually assume a uniform eruptive temperature.

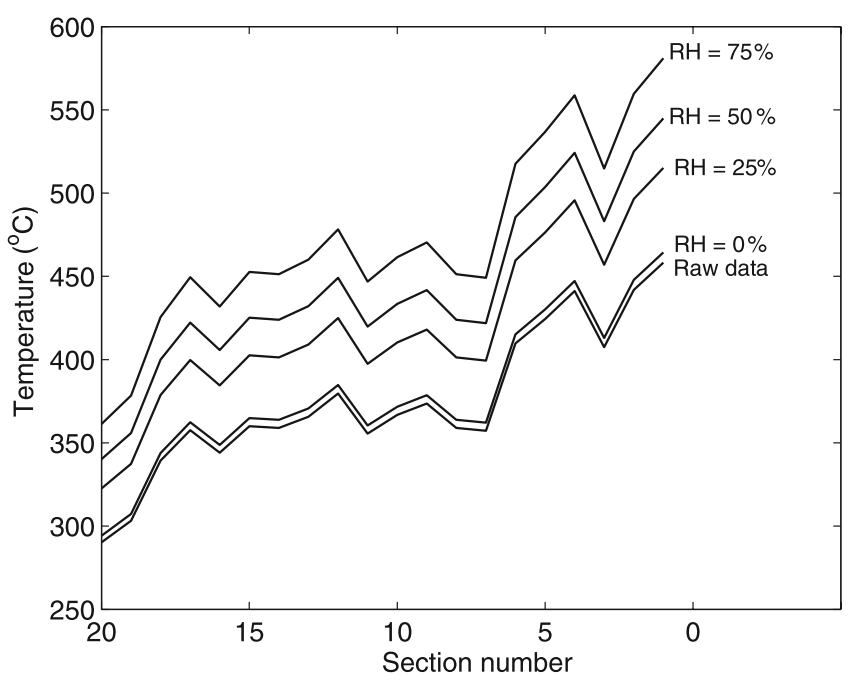

Figure 17. Temperature profiles from the thermal image mosaic taken from the helicopter. The direction of flow is from right to left. The data correspond to the area shown in Figure 16. The area was divided into 30 sections along the flow and the average flow temperature extracted. The lines represent the raw data; raw data corrected for emissivity, and the raw data corrected for emissivity and $\mathrm{RH}$ of $25 \%$, $50 \%$, and $75 \%$, respectively. 


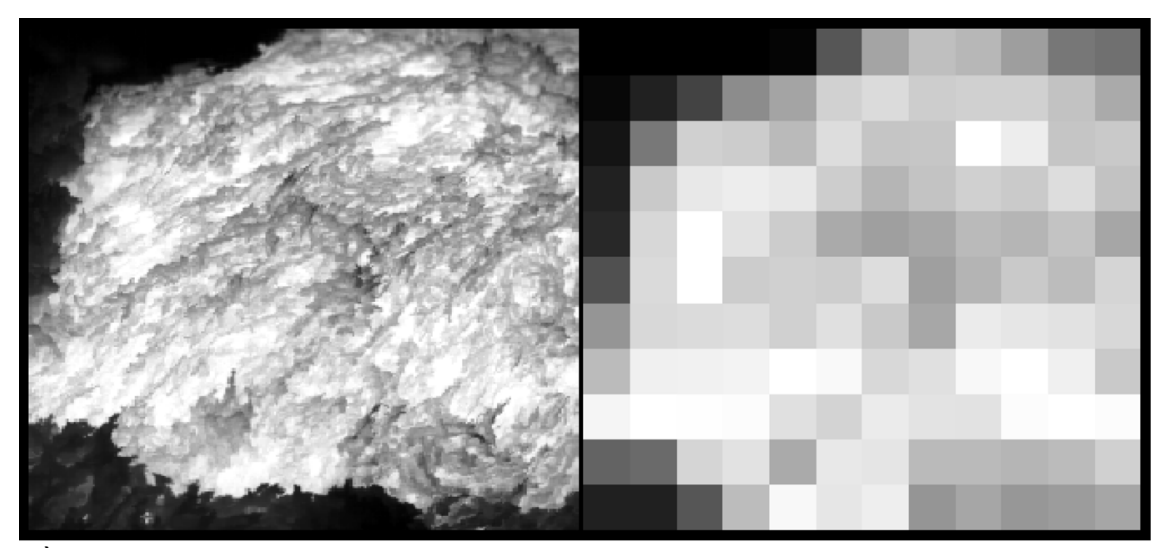

a)

b)

Figure 18. A high-resolution (1.5 m viewing distance) image (a) of lava emerging from a small vent on Mount Etna during the 1999 eruption and (b) an enlarged simulated low resolution (30 m viewing distance) of the same area.

[51] Figure 18b shows the calculated temperature distribution of the lava in Figure 18a at a viewing distance of $30 \mathrm{~m}$. This highlights problems in determining surface temperatures of lower resolution images. Each pixel gives a temperature based on the integrated radiance over the pixel area. Consequently, as pixel areas increase the maximum temperature recorded will decrease due to integration of radiance over larger areas. Therefore, as resolution decreases the pixel temperatures of the same area will tend toward the mean temperature derived from averaging the pixel temperatures from higher resolution images.

[52] Figure 19 shows normalized (to percentiles) histograms of the temperature distributions in the images in Figure 18. The simulated low-resolution image is noisier due to the smaller number of pixels. One of the most significant factors in reducing the resolution is the reduction in maximum derived temperature. In this example it drops from $\sim 1125^{\circ} \mathrm{C}$ to $1072^{\circ} \mathrm{C}$, a reduction of $53^{\circ} \mathrm{C}$ over a viewing distance of $30 \mathrm{~m}$. At a viewing distance of $\sim 250 \mathrm{~m}$, the image in Figure 18 will be represented by a single pixel and would give a temperature approximating that of the average image temperature of $930^{\circ} \mathrm{C}$. This is without any atmospheric attenuation correction. At $250 \mathrm{~m}$ the atmospheric correction for a target at $900^{\circ} \mathrm{C}$ and $50 \% \mathrm{RH}$ is $\sim 75^{\circ} \mathrm{C}$. Therefore a more realistic measured surface temperature would be $\sim 850^{\circ} \mathrm{C}$. This is $275^{\circ} \mathrm{C}$ lower than the high-resolution maximum temperature.

[53] Simulations of decreasing resolution can give insights into the effect of resolution on measurable temperatures. The simulation involves calculating radiance for each original pixel, averaging the radiances over a new pixel area (e.g., $2 \times 2,3 \times 3,4 \times 4$ etc), and converting the new radiance value back to temperatures. Only new pixel sizes that represent the entire original $160 \times 160$ pixel image are used. Figure 20 shows the effect of reducing the resolution of a $160 \times 160$ pixel section of the image in Figure 18. Simulation of resolution decrease has been undertaken until the original $160 \times 160$ pixel section is represented by a single pixel. Figure 20 shows that while the mean temperature remains relatively constant, the minimum and maximum measured temperatures rapidly converge on the mean value with increasing viewing distance until all are equal when the original image is represented by a single pixel.

\section{Conclusion}

[54] Controlled experiments reveal that the emissivity of basalt with a smooth surface ranged from 0.971 to 0.975 (mean of 0.973) while for the rough sample the emissivity range was 0.98 to 0.987 (mean of 0.983 ). The emissivity of smooth Etnean basalt decreases once the viewing angle from the horizontal drops below 50 degrees. This leads to apparent temperature errors of up to $\sim 60^{\circ} \mathrm{C}$. However, temperature measurements of rough samples are dominated by small-scale surface texture. Surface texture therefore

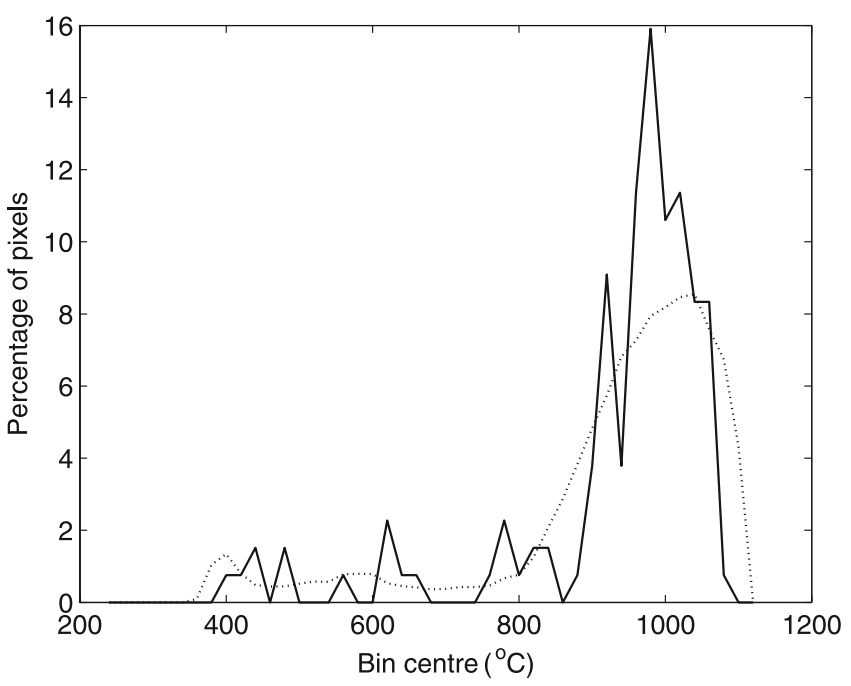

Figure 19. Histograms of the temperature data from Figure 18 . The histograms used a $20^{\circ} \mathrm{C}$ bin size and have been normalized to percentiles and show data from both the high-resolution (dotted) and simulated low-resolution (solid) images. 


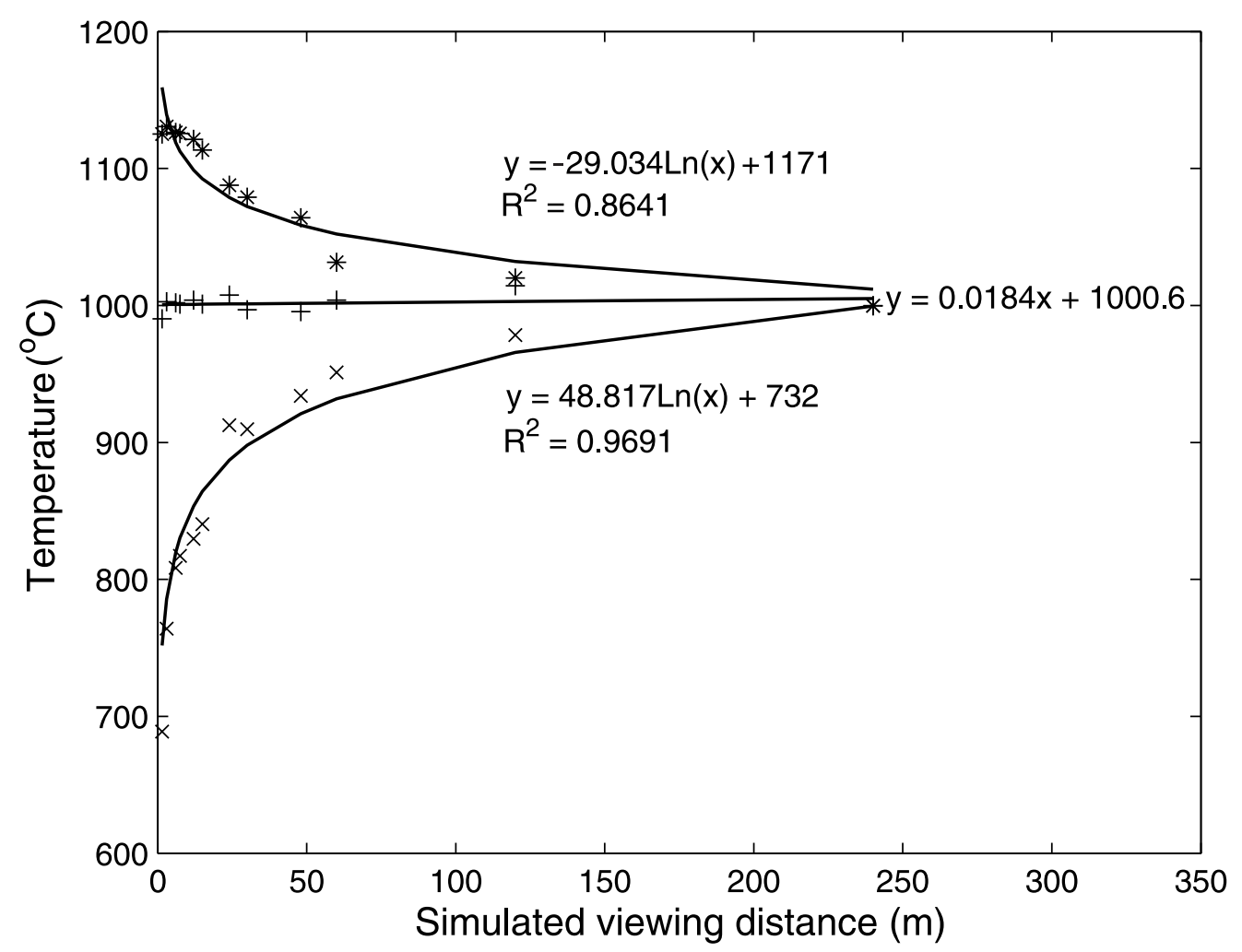

Figure 20. Graph of the minimum (cross), maximum (star), and mean (plus) temperatures of pixels in simulated images of increasing viewing distance from the original image.

plays an important part in the determination of surface temperatures. In the field it is likely that the emissivity will tend toward that of the rough sample due to the inherent roughness of most volcanic material.

[55] While the importance of measuring relative humidity during field campaigns is generally recognized, many workers make measurements only at the camera location and use this to correct for atmospheric attenuation. In view of the effect of this on apparent temperatures, we recommend that the minimum number of measurements required is two: one at the camera and another as close to the object being measured as possible. In cases where this is possible, measurements along the entire viewing path should be made and an integration of RH controlled atmospheric attenuation can be made.

[56] It has been shown that small increases in viewing distance cause significant variations in the temperatures measured by thermal imaging cameras. Simulated increase of viewing distance from 1.5 to $\sim 250 \mathrm{~m}$ for a small vent on Etna results in a decrease in measured maximum temperature of $275^{\circ} \mathrm{C}$. This simulation also indicates the relatively small viewing distances required to achieve singe pixel coverage of small thermal anomalies. At viewing distance $>250 \mathrm{~m}$, small vents on Etna would be subpixel in size for many FLIR camera lenses, and the temperature would be that derived from the integrated radiance from the vent and surrounding material, causing a significant drop in measured temperature.

[57] Using modeled minimum, maximum and mean temperature trends from sequences of simulated images at increased viewing distances, it is possible to determine temperature ranges of small Etna vents when only low-resolution images exist. Once sufficient images have been analyzed, it may be possible to determine the range of functions that characterize other parts of lava flows. In the meantime, by collecting images of lava flows over a range of viewing distances, functions similar to those shown in Figure 20 can be generated and extrapolated to determine temperature distributions of lava flows at small viewing distances. This is essential in the development of realistic cooling models, since, as can be seen in Figure 20, temperatures of some Etnean lavas on eruption spans a temperature range of $430^{\circ} \mathrm{C}$.

[58] The data shown in this paper are the results of laboratory experiments and computer simulations on field data. While the laboratory experiments provide compelling evidence for the effect of viewing angles on emissivity and the effect of surface texture on emissivity, careful assessment of the field environment is required prior to data analysis.

[59] During most eruptions, field measurements will not be possible at normal viewing angles unless they are made from the air, in which case only relatively low-resolution images will be obtained. The approach outlined in this paper reveals the magnitude of environmental and instrumental errors and how they can be minimized. We have shown that once appropriate corrections for atmospheric attenuation, emissivity, viewing angle and viewing distance have been made, thermal imaging cameras can provide useful temperature data on active volcanoes even if measurements are made at oblique viewing angles. The next stage in this investigation is to apply the results of this study to assess 
the validity of current lava flow cooling models; to determine the processes involved in the formation of the range of surface textures on lava flows; and to use images collected during eruptions on Etna (1999-2004) and Kilauea (2004) to better understand processes involved in the development of major flow fields.

[60] Acknowledgment. The authors would like to thank Sonia Calvari and INGV, Catania, Sicily, for assistance and logistical support during the 1999 Etna eruption; Kathy Cashman and an anonymous reviewer for their very helpful reviews; and Mike James for his assistance and advice during laboratory experiments.

\section{References}

Bailey, J. E., A. J. L. Harris, J. Dehn, S. Calvari, and S. Rowland (2006), The changing morphology of an open lava channel on Mt. Etna, Bull. Volcanol., 68, 497-515.

Burgi, P. Y., M. Caillet, and S. Haefeli (2002), Field temperature measurements at Erta'Ale Lava Lake, Ethiopia, Bull. Volcanol., 64, 472-485.

Calvari, S., and H. Pinkerton (2004), Birth, growth and morphologic evolution of the 'Laghetto' cinder cone during the 2001 Etna eruption, J. Volcanol. Geotherm. Res., 132, 225-239.

Calvari, S., L. Spampinato, L. Lodato, A. J. L. Harris, M. R. Patrick, J. Dehn, M. R. Burton, and D. Andronico (2005), Chronology and complex volcanic processes during the 2002-2003 flank eruption at Stromboli volcano (Italy) reconstructed from direct observations and surveys with a handheld thermal camera, J. Geophys. Res., 110 B02201, doi:10.1029/2004JB003129.

Crisp, J., and S. Baloga (1990), A model for lava flows with two thermal components, J. Geophys. Res., 95, 1255-1270.

Dehn, J., K. G. Dean, K. Engle, and P. Izbekov (2002), Thermal precursors in satellite images of the 1999 eruption of Shishaldin Volcano, Bull. Volcanol., 64, 525-534.

Dozier, J. (1981), A method for satellite identification of surfacetemperature fields of subpixel resolution, Remote Sens. Environ., 11, $221-229$.

Dozier, J., and S. G. Warren (1982), Effect of viewing angle on the infrared brightness temperature of snow, Water Resour. Res., 18, 1424-1434.

Flynn, L. P., and P. J. Mouginis-Mark (1994), Temperature of an active lava channel from spectral measurements, Kilauea Volcano, Hawaii, Bull. Volcanol., 56, 297-301.

Flynn, L. P., A. J. L. Harris, and R. Wright (2001), Improved identification of volcanic features using Landsat 7 ETM+, Remote Sens. Environ., 78, $180-193$.

Harris, A. J. L., and S. K. Rowland (2001), FLOWGO: A kinematic thermo-rheological model for lava flowing in a channel, Bull. Volcanol., 63 , $20-44$.

Harris, A. J. L., S. E. J. Swabey, and J. Higgins (1995), Automated thresholding of active lavas using AVHRR data, Int. J. Remote Sens., 16, $3681-3686$

Harris, A. J. L., L. P. Flynn, L. Keszthelyi, P. J. Mouginis-Mark, S. K. Rowland, and J. A. Resing (1998), Calculation of lava effusion rates from Landsat TM data, Bull. Volcanol., 60, 52-71.

Harris, A. J. L., E. Pilger, L. P. Flynn, H. Garbeil, P. J. Mouginis-Mark, J. Kauahikaua, and C. Thornber (2001), Automated, high temporal resolution, thermal analysis of Kilauea volcano, Hawaii, using GOES satellite data, Int. J. Remote Sens., 22, 945-967.

Harris, A. J. L., L. P. Flynn, O. Matias, W. I. Rose, and J. Cornejo (2004), The evolution of an active silicic lava flow field: An ETM+ perspective, J. Volcanol. Geotherm. Res., 135, 147-168.
Head, J. W., and L. Wilson (1986), Volcanic processes and landforms of Venus: Theory, predictions, and observations, J. Geophys. Res., 91, 9407-9446.

Incropera, F. P., and D. P. De Witt (1985), Introduction to Heat Transfer, pp. 654-746, John Wiley, Hoboken, N. J.

James, M. R., R. Robson, H. Pinkerton, and M. Ball (2006), Oblique photogrammetry with visible and thermal images of active lava flows, Bull. Volcanol., 69, 105-108.

Keszthelyi, L., and R. Denlinger (1996), The initial cooling of pahoehoe flow lobes, Bull. Volcanol., 58, 5-18.

Labed, J., and M. P. Stoll (1991), Angular variation of land surface spectral emissivity in the thermal infrared: Laboratory investigations on bare soils, Int. J. Remote Sens., 12, 2299-2310.

Lautze, N. C., A. J. L. Harris, J. E. Bailey, M. Ripepe, S. Calvari, J. Dehn, S. K. Rowland, and K. Evans-Jones (2004), Pulsed lava effusion at Mount Etna during 2001, J. Volcanol. Geotherm. Res., 137, 231-246.

Mouginis-Mark, P. J., and P. W. Francis (1992), Satellite observations of active volcanoes: Prospects for the 1990s, Episodes, 15, 46-55.

Mouginis-Mark, P., S. Rowland, J. Crisp, L. Glaze, K. Jones, A. Kahle, D. Pieri, H. Zebker, A. Krueger, and L. Walter (1991), Analysis of active volcanoes from the Earth observing system, Remote Sens. Environ., 36, $1-12$.

Oppenheimer, C., and P. Francis (1997), Remote sensing of heat, lava and fumarole emissions from Erta'Ale volcano, Ethiopia, Int. J. Remote Sens., $18,1661-1692$

Oppenheimer, C. M. M., and D. A. Rothery (1991), Infrared monitoring of volcanoes by satellite, J. Geol. Soc., 148, 563-569.

Pinkerton, H., and L. Wilson (1994), Factors controlling the lengths of channel-fed lava flows, Bull. Volcanol., 56, 108-120.

Pinkerton, H., M. James, and A. Jones (2002), Surface temperature measurements of active lava flows on Kilauea volcano, Hawai'i, J. Volcanol. Geotherm. Res., 113, 159-176.

Rothery, D. A., P. W. Francis, and C. A. Wood (1988), Volcano monitoring using short wavelength infrared data from satellites, J. Geophys. Res., 93, $7993-8008$

Rowland, S. K., A. J. L. Harris, M. J. Wooster, F. Amelung, H. Garbeil, L. Wilson, and P. J. Mouginis-Mark (2003), Volumetric characteristics of lava flows from interferometric radar and multispectral satellite data: The 1995 Fernandina and 1998 Cerro Azul eruptions in the western Galapagos, Bull. Volcanol., 65, 311-330.

Sabins, F. F. J. (1978), Remote Sensing Principles and Interpretations, W. H. Freeman, New York

Self, S., and P. J. Mouginis-Mark (1995), Volcanic eruptions, prediction, hazard assessment, remote sensing, and societal implications, Rev. Geophys., 33, 257-262.

Sobrino, J. A., and J. Cuenca (1999), Angular variation of thermal infrared emissivity for some natural surfaces from experimental measurements, Appl. Opt., 38, 3931-3936.

Vaughan, R. G., S. J. Hook, M. S. Ramsey, V. J. Realmuto, and D. J. Schneider (2005), Monitoring eruptive activity at Mount St. Helens with TIR image data, Geophys. Res. Lett., 32, L19305, doi:10.1029/ 2005GL024112.

Wolfe, W. L., and G. J. Zissis (Eds.) (1978), The Infrared Handbook, The Office, Washington, D. C.

Wright, R., and L. P. Flynn (2003), On the retrieval of lava-flow surface temperatures from infrared satellite data, Geology, 31, 893-896.

Zebker, H. A., P. Rosen, and S. Hensley (1996), Analysis of active lava flows on Kilauea volcano, Hawaii, using SIR-C radar correlation measurements, Geology, 24, 495-498.

M. Ball and H. Pinkerton, Department of Environmental Science, Lancaster Environment Centre, University of Lancaster, Lancaster LA1 4YQ, UK. (h.pinkerton@lancaster.ac.uk) 